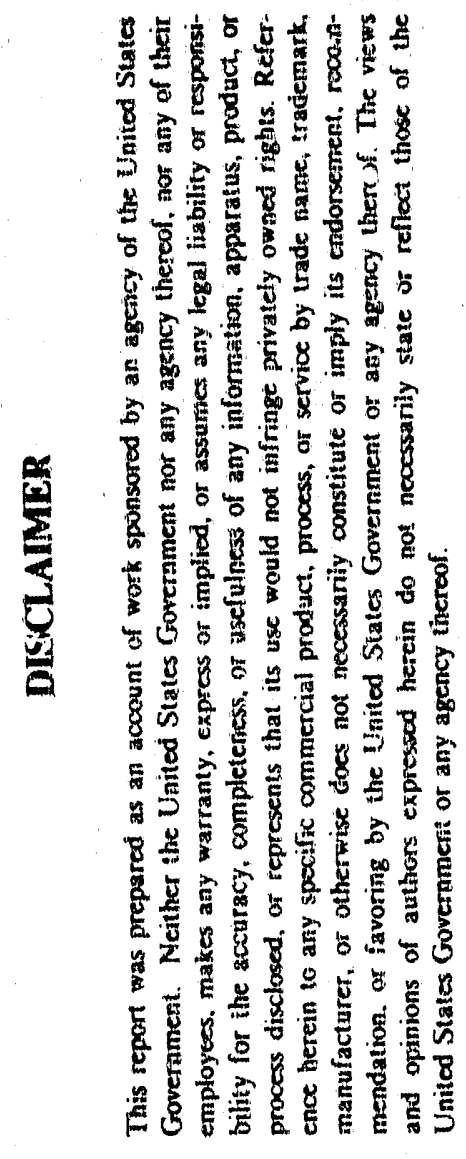

DOE/PC/90751--174

DE92 040531

\section{TRANSFORMATIONS OF INORGANIC COAL CONSTITY ENTS \\ IN COMBUSTION SYSTEMS}

\author{
Quarterly Report No. 22 \\ for the Period
}

January 1 - March 31, 1992

\section{PSI TECHNOLOGY COMPANY}

Principal Authors:

Dr. Joseph J. Helble and Dr. Arthur A. Boni

PSI Technology Company

20 New England Business Center

Andover, MA 0.1810

Prof. Frank E. Huggins, Prof. Gerald P. Huffman, and Dr. Naresh Shah

University of Kentucky

Department of Chemical Engineering

Lexington, KY 40506

DATE PUBLISHED - JULY 1992

Prepared Under

Contract No. DE-AC22-86PC90751

U.S. DEPARTMENT OF ENERGY

Pittsburgh Energy Technology Center

P.O. Box 10940

Pittsburgh, PA 15236-0940 


\section{TABLE OF CONTENTS}

Section

Page

1.

EXECUTIVE SUMMARY

2. INTRODUCTYON AND OVERVIEW OF PRO JRAM TASKS

3.

ADVANCED TECHNIQUES FOR COAL, MINERAL, AND ASH CHARACTERIZATION Introduction

XAFS Spectroscopy

3-3

Results and Discussion

$3-4$

Conclusions

$3-6$

References

$3-6$

4.

IDEALIZED COMBUSTION DETERMINATION OF ASH PARTICLE FORMATION AND SURFACE STICKINESS

$4-1$

Ash Particle Chemistry

$4-3$

4.1

Deposit Compositions

4-5

4.2

Soluble Additive Effects 
SECTION 1

EXECUTIVE SUMMARY

$1-1 / 1-2$ 


\section{EXECUTIVE SUMMARY}

The technical objectives of this project are:

a. To: 1) define the partitioning of inorganic constituents associated with raw coal particles among products (including vapors, aerosols, and residual char/ash particles) formed under conditions representative of pulverized coal flames as a function of the specific (intrinsic and extrinsic) characteristics of the raw coal and the environment in which the transformations occur; and 2) characterize the resultant spectrum of products in detail.

b. To elucidate and quantify the fundamental processes (involving basic principles of physics, chemistry, thermodynamics) by which transformations of the inorganic constituents occur.

c. To develop, based on the information required in a. and b. above, a tractable "process" model capable of predicting the significant features of the transformation process, most importantly, the nature and distribution of products.

The contract approach and description of each task is included in Section 2 of this report. This report summarizes work accomplished during the twenty-second quarter of this project.

The work discussed herein highlights recent accomplishments: at the University of Kentucky (UK), where XAFS analysis of the forms of chromium in coal and ash samples has been completed; and at PSI Technology Co. (PSIT), where analysis of testing data collected during a joint test with the State Electricity Cornmission of Victoria (SECV) has continued.

In Section 3 of this report, results from recent UK chromium XAFS analysis of several coal and ash samples are reported. Illinois \#6 parent coal, Mllinois \#6 physically beneficiated coal, and two coals from the Penn Stite Coal Bank (DECS-2 and DECS-12), were found to contain chromium in the +3 oxidation state. No evidence for the carcinogenic and toxic +6 oxidation state (i.e., $\mathrm{CrO}_{4}{ }^{-2}$ ) was found. Ash samples were generated from each of these coals in a PSIT laboratory scale reactor at $1500^{\circ} \mathrm{C}$ and $7 \%$ oxygen. Subsequent XAFS analysis of these ash samples also identified only $\mathrm{Cr}+3$ in the ash. As discussed further in Section 3, if the results of this study can be considered general for bituminous coals, then the absence of the $(+6)$ chromate state in both the coal and the ash implies that the hazard posed by chromium in coal combustion is small, absent high concentrations of chromium in the ash (> $100 \mathrm{ppm}$ ).

In Section 4 of this report, additional PSIT analysis of UK-generated CCSEM data for ash simples collected in joint testing with SECV is presented. Analysis of Loy Yang samples indicated that treating the coal with a soluble aluminum/magnesium additive decreased the sodium, chlorine, and silicon contents of the ash, and consequently made deposits easier to remove from cooled tube surfaces. Analysis of Beulah lignite deposit data 
indicated that iron concentrations were greatest in the short residence time deposits, suggesting deposition of molten pyrite products. Sample-to-sample differences in the deposit composition were small, however, making it difficult to conclude much more from the Beulah deposit analyses.

The Final Report is currently being prepared, and shall constitute the next major submission from this project. 
SECTION 2

INTRODUCTION AND OVERVIEW OF PROGRAM TASKS

$2-1 / 2-2$ 


\section{INTRODUCTION AND OVERVIEW OF PROGRAM TASKS}

This project consists of an integrated series of experimental and modeling tasks performed by PSI Technology Company (PSIT) and three subcontractors (identified below) to achieve the project objectives. Additional work is to be conducted jointly with the University of North Dakota Energy and Environmental Research Center (UND EERC) and the State Electricity Commission of Victoria, Australia (SECV) through cooperative agreements. Important elements of this work include coal and ash characterization using advanced analytical techniques, testing in sniall scale furnaces, testing in moderate to large-pilot scale units, adaptation of fundamental submodels developed previously to beneficiated coal systems, and integration of these submodels and experimental findings into an engineering model used to predict ash particle composition and size distributions. A breakdown of the work to be performed in each task is presented below.

\section{Task 1 - Program Planining, Management. Reporting, and Peer Review}

This task, to be performed by PSIT, consists of: (1) preparation and annual updating of a Program Plan; (2) overall coordination, management, and integration of the subcontracts and project results; (3) preparation of project monthly reports; (4) integration and final preparation of project quarterly reports; and (5) conduct of serni-annual peer review and project coordination meetings of the project Principal Investigators.

\section{Task 2 - Coal Selection, Preparation, and Characierization}

This task will be performed by PSIT using the guidelines for mineralogy-based coal selection developed by Foster Wheeler Development Corporation (FWDC) ciuring the first phase of this project. Five parent coals plus one beneficiated sample of each coal with an optional two sets of additional coals will be selected to permit an experimental determinition of beneficiation related variables on inorgani? transformations during combustion. Emphasis will be placed on obtaining both eastern and western coals, cleaned with currently accepted and advanced beneficiation strategies. Coals will be acquired by PSIT, pulverized as necessary by an independent contractor on a purchase order basis, and shipped to the various investigators.

\section{Task 3 - Advanced Techniques for Coal and Mineral Characterization}

The University of Kentucky (UK) will apply advanced analytical techniques to determine the form, size, and associations of the coal minerals and the resulting ash particles. Work to be performed in this broad area can be broken down into three Subtasks. Under Subtask 3.1, UK will work with other research groups to make improvements in the computer controlled scanning electron microscopy (CCSEM) technique. This will include software improvernents to permit the CCSEM to distinguish between extraneous and included mineral matter in an automated fashion. Under Subtask 3.2, UK will apply CCSEM, Mössbauer spectroscopy, $\mathbf{x}$-ray absorption fine structure analysis (XAFS), and scanning transmission electron microscopy (STEM) to analyze the mineral forms in tis parent coals 
and the resulting ash products. X-ray diffraction will also be used as needed for mineral analysis. Under Subtask 3.3, UK will develop an in-situ XAFS capability at the Brookhaven National Laboratories (BNL) Light Source, to be used to determine the associations of inorganic species in ash particles and initial sticky particle layers without the complications posed by quenching and extractive sampling.

Task 4 - Fundamental Studies of Selected Ash Vaporization, Nucleation, Condensation, and Coagulation Phenomena

Task 4, to be performed by PSIT, involves thermochemical modeling of the inorganic species expected to be present in the parent coal particles, the beneficiated coal particles, and the final ash particles at various combustion conditions.

\section{Task 5. Fundamental Studies of Mineral Matter Vaporization and Residual Ash Formation}

Experimental and modeling studies are to be conducted at the Massachusetts Institute of Techrology (MIT) on two Subtasks. Under Subtask 5.1, drop tube furnace combustion experiments will be conducted with parent coals, beneficiated coals, and model chars to assess the importance of the various mechanisms which control residual ash formation. Emphasis will be placed on the expected increasing importsuce of char fragmentation in shaping the distribution, both experimentally and through adaptation of the percolative fragmentation model developed in the first phase of this project. In Subtask 5.2, the extent of vaporization of inorganic species contained in the parent and beneficiated coals will be examined experimentally. Vaporization models developed previously will be utilized to interpret results from beneficiated systems.

\section{Task 6 - Pulverized Coal Combustion Studies of Ash Enrichment by Volatiles}

The objectives of this task, to be performed at the University of Arizona (UA) self-sustained reactor facility, are to determine the different fume amounts, compositions, and structures resulting from various beneficiation processes. Mechanistic descriptions of the size and surface composition of the submicron fume formed during combustion will be developed. Testing will occur on selected parent and cleaned coals, chosen subsequent to initial screening in the PSIT reactor facility. As part of this effort, the size of the residual ash piticles will be measured in-situ using an optical single particle measuring instrument provided by PSIT. A model capable of describing the general ash particle size distribution including the effects of fume formation and char fragmentation will also be developed.

\section{Task 7 - Idealized Combustion Determination of Ash Particle Formation and Surface} Stickiness

In this task, PSIT will employ an idealized combustion system to determine ash particle size and composition distributions for comparison with results obtained at MIT and UA. Emphasis will be placed on quantifying the amount of fume, and the amount and chemical composition of ash generated from the various beneficiated coals. Particle 
stickiness as it pertains to inertial impaction and thermophoretic deposition will be addressed. Particle size will be analyzed by several means as part of the task, including CCSEM, laser diffraction, and aerodynamic impaction. In addition, the combustor portion of an in-situ XAFS cell will be designed and constructed. Experiments utilizing this cell will be conducted with UK and BNL at the BNL. Light Source to determine ash composition and sticky particle composition in-situ.

\section{Task 8 - Model Development and Integration}

In this task, PSIT will synthesize the mineral redistribution, char particle fragmentation, and mineral transformation models developed under the various tasks into an overall ash formation model. The result of this synthesis will be an engineering model capable of describing the size and, more impor iantly, the chemical composition of residual ash generated during pulverized coal combustion and the quantity and composition of the ash fume. The information provided by this model will then be used to assess the benefits of coal cleaning though a parametric study of ash properties resulting from selective mineral removal. 


\section{SECTION 3}

ADVANCED TECHNIQUES FOR COAL, MINERAL, AND ASH CHARACTERIZATION

Frank E. Huggins, Naresh Shah, and G. P. Huffman, Institute for Mining and Minerals Research University of Kentucky, Lexington, KY 40506. 


\section{ADVANCED TECHNIQUES FOR COAL, MINER.AL, AND ASH CHARACTERIZATION}

\subsection{Introduction}

In order to understand the behavior of a given element in coal combustion and waste disposal and perhaps remedy some of the potential problems associated with environmental contamination by hazardous trace elements, it is not enough just to determine the amount of an element in the coal and various waste fractions. It is essential to know also how the element occurs in the coal and other fractions. The mode or form of occurrence of the element in the coal controls to a great extent the potential hazard posed by the element to human health and the environment.

There are many different methods of quantitatively determining the amount of an element in coal; such methods include atomic absorption, X-ray fluorescence, instrumental neutron activation analysis, proton induced X-ray or gamma-ray emission, inductively coupled plasma techniques, etc. However, there are very few methods for determining the forms of occurrence of a trace element in materials as complex as coal, ash, or siags. A technique that has excellent demonstrated potential for investigating the forms of occurrence of trace elements in coal and other materials is X-ray absorption fine structure (XAFS) spectroscopy [1-3]. This technique has the ability to focus on a specific element in a material and to provide detailed information relevant to the local bonding and structure of the element in the material, from which the form of occurrence can usually be deduced. Furthermore, this technique is both direct and nondestructive. In this report, the application of XAFS spectroscopy to the speciation of trace element species is demonstrated by a preliminary survey investigation of chromium in coal and ash. This element has been identified as potentially hazardous to the environment in the 1990 Amendments to the Clean Air Act.

\subsection{XAFS Spectroscopy}

XAFS spectroscopy was performed at beam-line X-19A at the National Synchrotron Light Source, Brookhaven National Laboratory. For trace amounts of chromium in coals and ash samp'es, the absorption of X-rays was measured over the spectral range from 5.9 to $6.2 \mathrm{keV}$; over the X-ray absorption near-edge structure (XANES) region (5.97 to $6.03 \mathrm{keV}$ ), absorption data were collected every $0.2 \mathrm{eV}$. Absorption of the X-rays for trace chromium samples was measured by means of a thirteen-element germanium array detector [4] that detected the fluorescent X-rays only in a specified tunable energy window that corresponded to the energy of the chromium fluorescent $\mathrm{K}_{\alpha} \mathrm{X}$-rays. In addition, a $6 \mu$ vanadium filter was used to minimize background. Up to ten scans were recorded and summed for the weakest absorbers. The spectral summations, the pulse-height windowing, and the low-energy filtering all contributed to enhance the signal-to-noise ratio of the trace element spectra. For reference standards, conventional ion chambers were used to measure both the fluorescent and absorption XAFS spectra in a single scan. Depending on the amount of chromium in the 
standard, the standard was diluted in graphite to optimize the absorption spectrum. As is normally done, the chromium XAFS spectra were divided into separate XANES and EXAFS regions, and standard XAFS analysis methods were employed to analyze the spectral regions. However, for many of the trace chromium coals and ash samples, the chromium EXAFS region was terminated by a surprisingly strong $\mathrm{Ce}_{\mathrm{II}}$ absorption edge at about $175 \mathrm{eV}$ above the $\mathrm{Cr} \mathrm{K}$ edge, which effectively made the EXAFS region uninformative for chromium in such samples. The zero energy point $(5.989 \mathrm{keV})$ for chromium was defined as the first inflection point in the XAFS spectrum of chromium metal foil.

\subsection{Results and Discussion}

It is a relatively easy matter to discriminate by means of XAFS spectroscopy among the two most common oxidation states of chromium, $\mathrm{Cr}^{3+}$ and $\mathrm{CrO}_{4}{ }^{2-}$, found in natural and environmental samples. Chromium XAFS spectra of two chromic oxide and two chromate samples are shown in Figure 3.1. The chromate oxidation state is characterized by the presence of a large pre-edge feature at about $0 \mathrm{eV}$ that is highly distinctive of first series transition metal $3 \mathrm{~d}^{0}$ species in tetrahedral coordination by oxygen anions. In addition, it should be noted that the maximum absorption in the chromate species occurs at about 40 to $50 \mathrm{eV}$, at which energy a minimum in the absorption occurs for the $\mathrm{Cr}^{3+}$ compounds. These observations appear to be quite general and to apply to all the chromium standards so far examined.

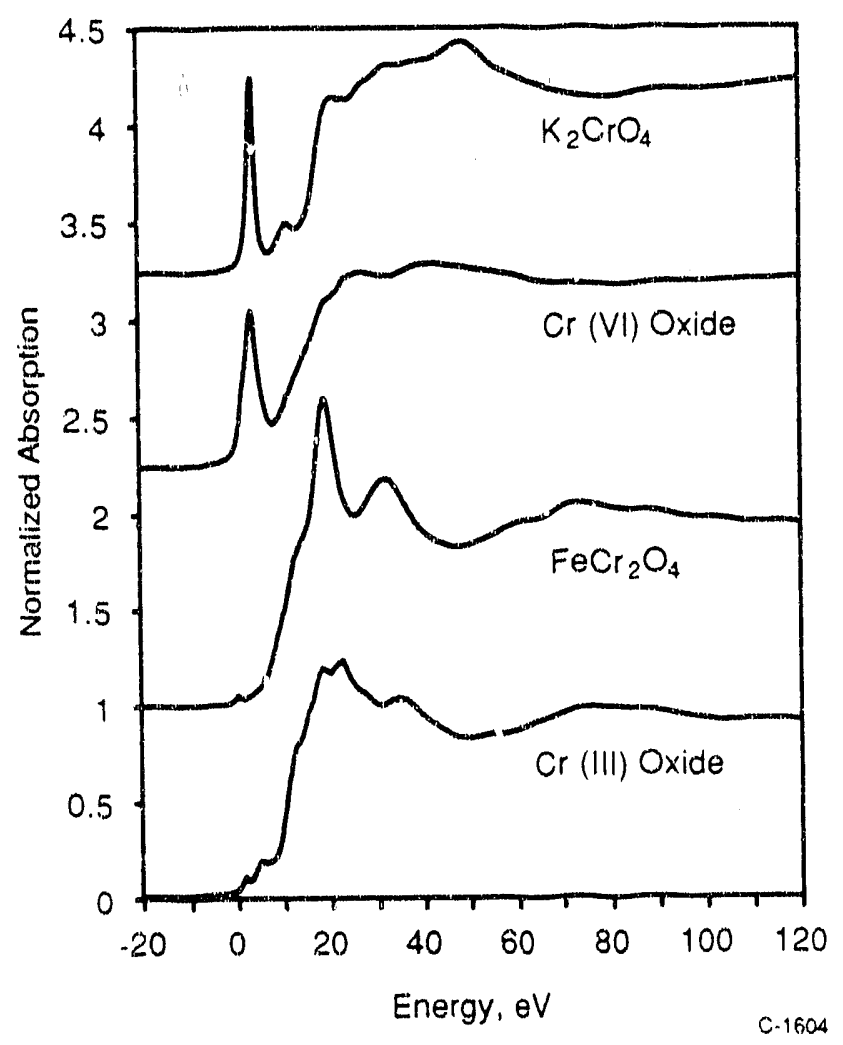

Figure 3.1 Cr K-edge XANES specira of several chromium standards. 
Figure 3.2 shows chromium XAFS ipectra obtained for Illinois $\$ 6$ coal and ash samples. The spectra of the parent and the cleaned product of the spherical oil agglomeration process (S.O.A.P.) are virtually identical in appearance and clearly demonstrate that al: ( $>95 \%$ ) of the chromium is present in the $\mathrm{Cr}^{3+}$ oxidation state. In addition, the abundance of chromium in the two samples is essentially the same. These observations suggest that there is only one significant chromium form of occurrence and that it is not strongly associated with the mineral matter, otherwise the chromium abundance would have dropped significantly upon cleaning and the XAFS spectrum would have shown significant variation. Chromium in the ash sample is also predominantly $\mathrm{Cr}^{3+}$, although the spectral shape differs somewhat from that of the coal samples.

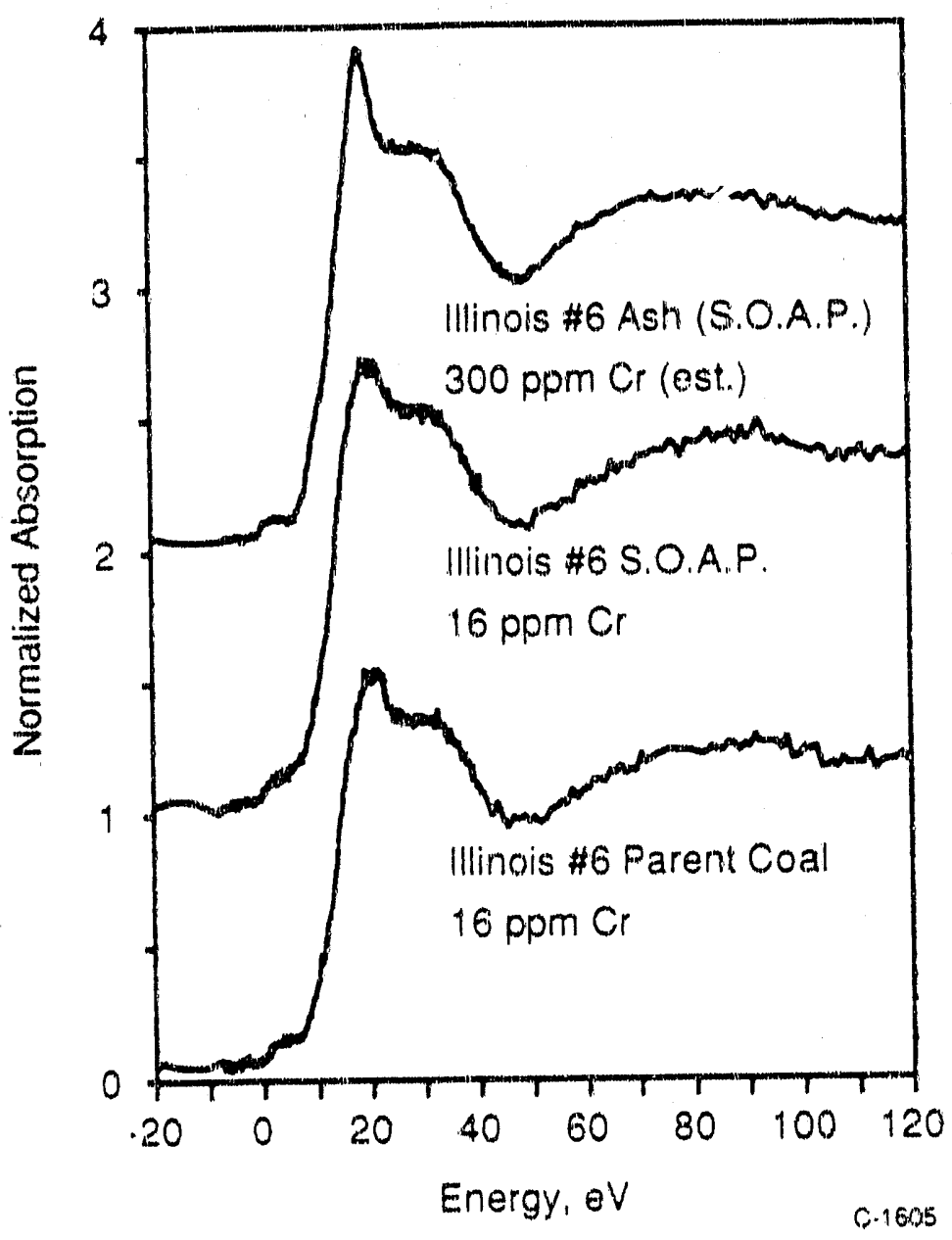

Figure 3.2. Cr K-edge XANES spectra of Illinois \#6 parent and cleaned coals, and ash samples derived from these coals. 


\subsection{Conclusions}

Of the two major oxidation states of chromium, the $\mathrm{CrO}_{4}{ }^{2-}$ oxidation state can be both toxic and carcinogenic, whereas the $\mathrm{Cr}^{3+}$ cxidation state at such low concentration levels $(<100 \mathrm{ppm}$ ) does not pose a significant health risk [5]. If the results of this study can be considered to be general, then the absence of the chromate state in both coal and combustion ash would imply that the hazard posed by chromium in coal utilization is minimal.

\subsection{References}

1. J. Wong, C.L. Spiro, D.H. Maylotte, F.W. Lytle, and R.B. Greegor, in EXAFS and Near-Edge Structure III, (eds. K.O. Hodgson, B. Hedman, and J.E. Penner-Hahn), Springer Proc. Phys. 2, 362-367, (1984),

2. J.E. Silk, L.D. Hansen, D.J. Eatough, M.W. Hill, N.F. Mangelson, F.W. Lytle, and R.B. Greegor, Physica B (Proceedings, YAFS V), 158, 247-248, (1989).

3. F.E. Huggins, G.P. Huffman, and S.H. Bauer, J. Coal Qual., 8(3.4), 119, (1989).

4. S.P. Cramer, O. Tench, N. Yocum, and G.N. George, Nucl. Instr. Meth. A266, 586-591, (1988).

5. N. Tietz (Ed.), "Clinical Guide to Laboratory Tests", (2nd. Edition), W. B. Saunders, Philadelphia, PA, (1990). 


\title{
SECTION 4
}

\section{IDEALIZED COMBUSTION DETERMINATION OF ASH PARTICLE} FORMATION AND SURFACE STICKINESS

\author{
J.J. Helble and J.W. Moore \\ PSI Technology Company \\ 20 New England Business Center \\ Andover MA 01810
}

\author{
and \\ G. Domazetis \\ State Electricity Commission of Victoria \\ Herman Research Laboratory \\ 677 Springuale Road \\ Mulgrave VIC 3170
}




\section{IDEALIZED COMBUSTION DETERMINATION OF ASH PARTICLE FORMATION AND SURFACE STICKINESS}

During the previous quarter, PSI Technology Co. continued analyzing CCSEM data on samples collected during joint testing with the State Electricity Commission of Victoria (SECV). Three separate areas are briefly discussed: 1) examination of combustion scale effects on the chemistry of individual ash particles; 2) examination of deposit compositions as a function of position (i.e., temperature) within the SECV $35 \mathrm{~kg} / \mathrm{h}$ reactor; and

3 ) examination of the effects of adding soluble aluminum and magnesium compounds to the Loy Yang 1953 coal prior to combustion as a means of controlling ash deposition. Results are described briefly in the following paragraphs.

\subsection{Ash Particle Chemistry}

One of the objectives of the tests conducted at SECV was to examine the effects of combustion scale on the chemistry of individual ash particles. Previous work conducted at PSIT and the University of Arizona had demonstrated that the distributions of individual particle compositions obtained in the PSIT 1,000 to 10,000 Btu/h reactor were the same as those obtained it the University of Arizona $100,000 \mathrm{Btu} / \mathrm{h}$ facility. These similarities suggested that the fundamental processes controlling ash particle formation were dominated by the coal particle size, coal mineralogy, and overall combustion conditions (temperature, oxygen) and not combustor scale (i.e., heating rare and particle number density in the flow stre im). To pursue this work further, additional tests were conducted at the sECV $35 \mathrm{~kg} / \mathrm{h}$ (nominal 1 million Btu/h) facility with Beulah lignite coal from this program. A detailed description of the facility and preliminary test results were reported in previous Quarterly Reports (e.g., Quarterly Report 21, submitied April 1992).

Recently the CCSEM results have been compared to determine whether ash particle chemical compositions measured at SECV were consistent with those measured elsewhere in this program. Results of a comparison for the calcium-aluminum-silicon system are shown in Figure 4.1. The figure labelled "coal" shows all minerals within the Beulah lignite coal containing at least $80 \% \mathrm{Ca}+\mathrm{Al}+\mathrm{Si}$ on a molar basis. The figure labelled "PSIT" shows the same plot for ash particles generated at PSIT under combustion conditions of $1500 \mathrm{~K}$ gas temperature, 7\% oxygen in nitrogen. The figure labelled "UA" is for ash generated at the University of Arizona self-sustained combustion facility at a flame temperature of $1300^{\circ} \mathrm{C}$, and the figure labelled "SECV" is for data obtained at SECV (electrostatic precipitator sample). Each point on the figures represents a particular $\mathrm{Ca}-\mathrm{Al}-\mathrm{Si}$ ratio, and the height of each peak represents the normalized number of particles in the sample with that composition. Significant calcium aluminosilicate formation has occurred in all samples, indicating that the interaction of dispersed or organically bound calcium with kaolinite minerals is not affected by the scale of the combustion process. 

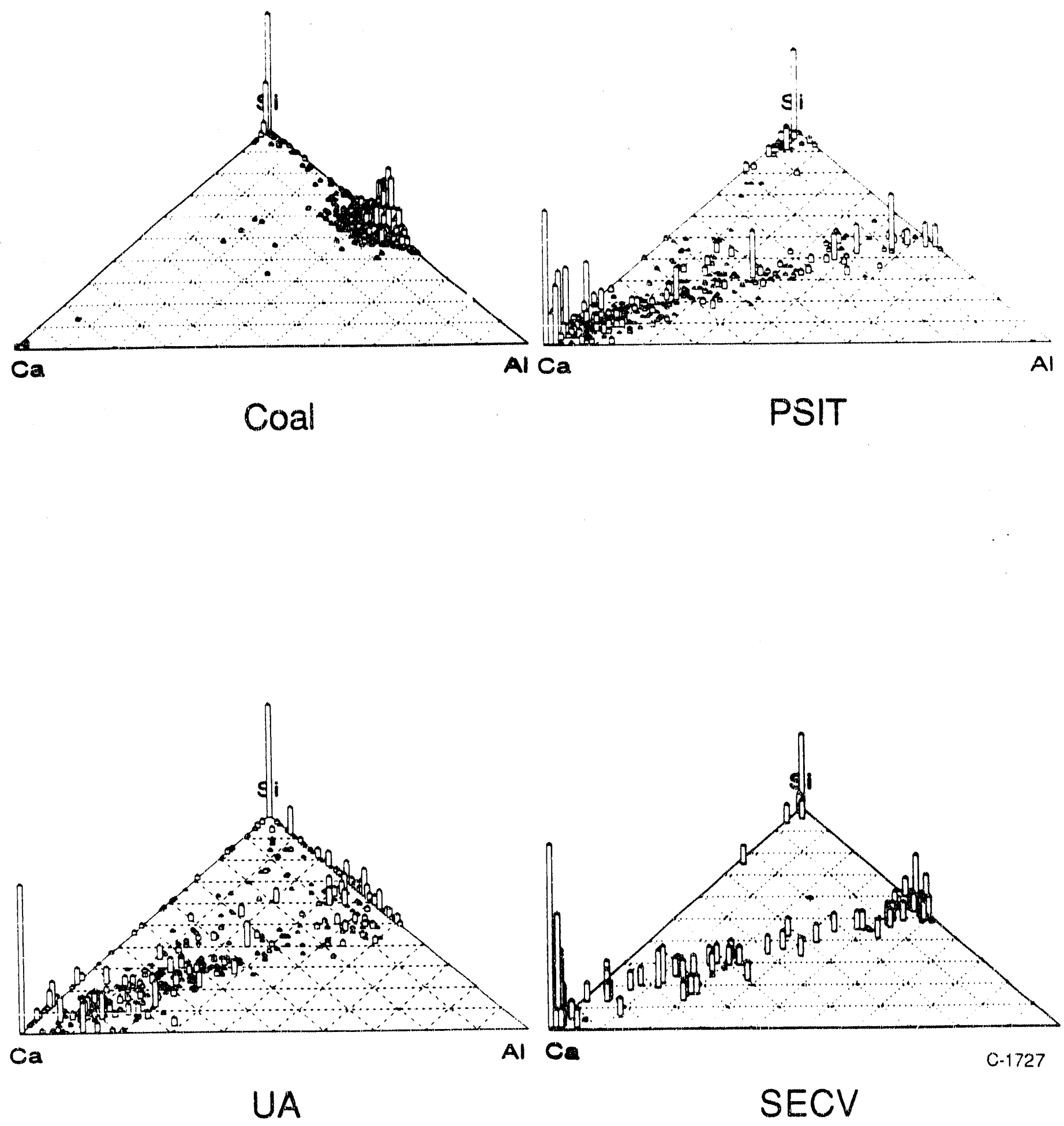

Figure 4.1 Ca-Al-Si ternary diagrams for Beulah lignite coal and ash samples generated from combustion of Beulah at three separate facilities. 


\subsection{Deposit Compositions}

As discussed in Quarterly Report 21, deposit samples were collected with cooled and uncooled probes at several points within the combustor. The normalized chemical composition for several key elements from these samples, as determined at SECV, is plotted in Figure 4.2. $\mathrm{SO}_{3}$ concentrations are highest in the longest residence time (coolest temperature) deposits, indicating substantial sulfation of calcium within the ash. Iron oxide concentrations are slightly higher at shorter residence times, possibly suggesting deposition of large molten pyrite-derived products. Calcium oxide concentrations are highest in samples collected from the cooled deposition tube banks, possibly indicating the existence of sticky calcium aluminosilicate ash particles at this point in the system. Differences in calcium oxide and iron oxide concentrations along the length of the test facility are relatively small. They are, however, consistent with observations made in laboratory tests with Beulah at PSIT.

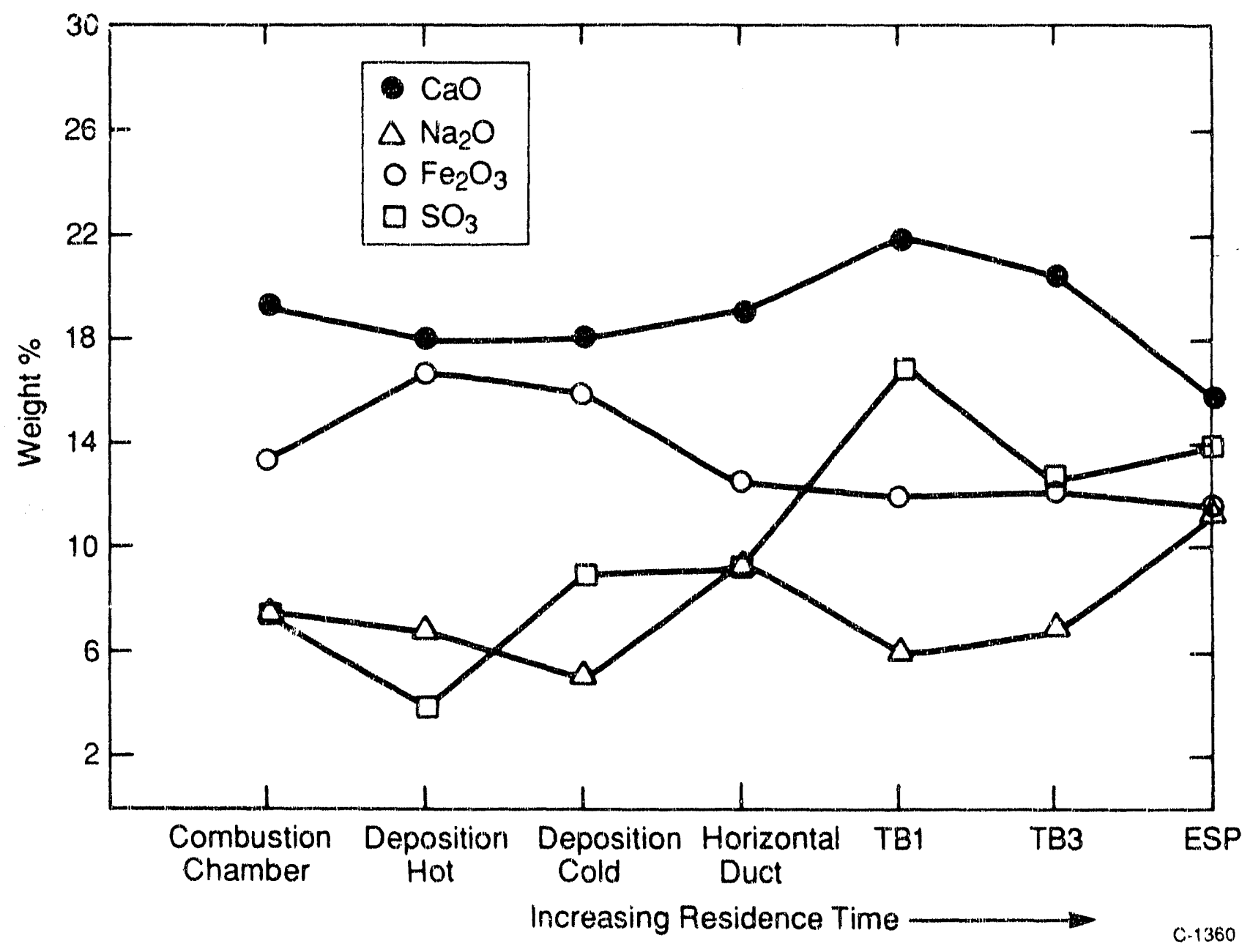

Figure 4.2 Normalized deposit compositions as a function of position for Beulah lignite testing. 


\subsection{Soluble Additive Effects}

Deposit and extractive particle sample compositions for ash samples generated during combustion of Loy Yang 1953 brown coal, and Loy Yang 1953 treated with soluble aluminum and magnesium additives are shown in Figure 4.3. The sodium, chlorine, and silicon contents of the deposits and the ash all decreased upon addition of the refractory additives. As noted in prior reports, the deposits generated during combustion of the treated Loy Yang were "fluffy" and hence easily removed. This suggests that this treatment process may be a viable means of controlling deposition during combustion of Loy Yang coals. 

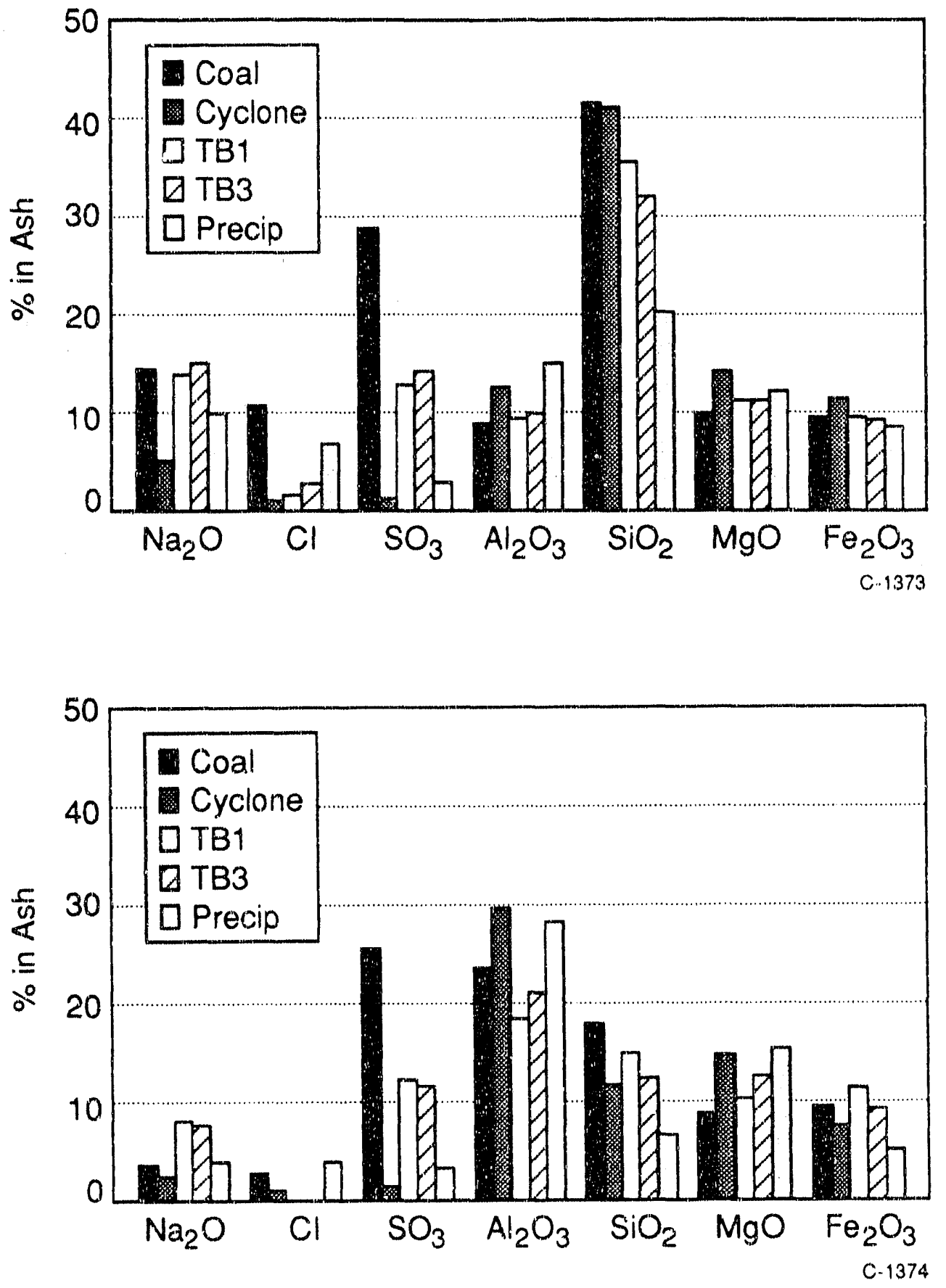

Figure 4.3 Deposit and particle samples for ash generated during combustion of Loy Yang 1953 and treated Loy Yang 1953 at SECV. "Cyclone" refers to samples removed with an extractive sampling probe slightly downstream of the combustion chamber exit. "Precip" refers to samples removed from the electrostatic precipitator hopper. 

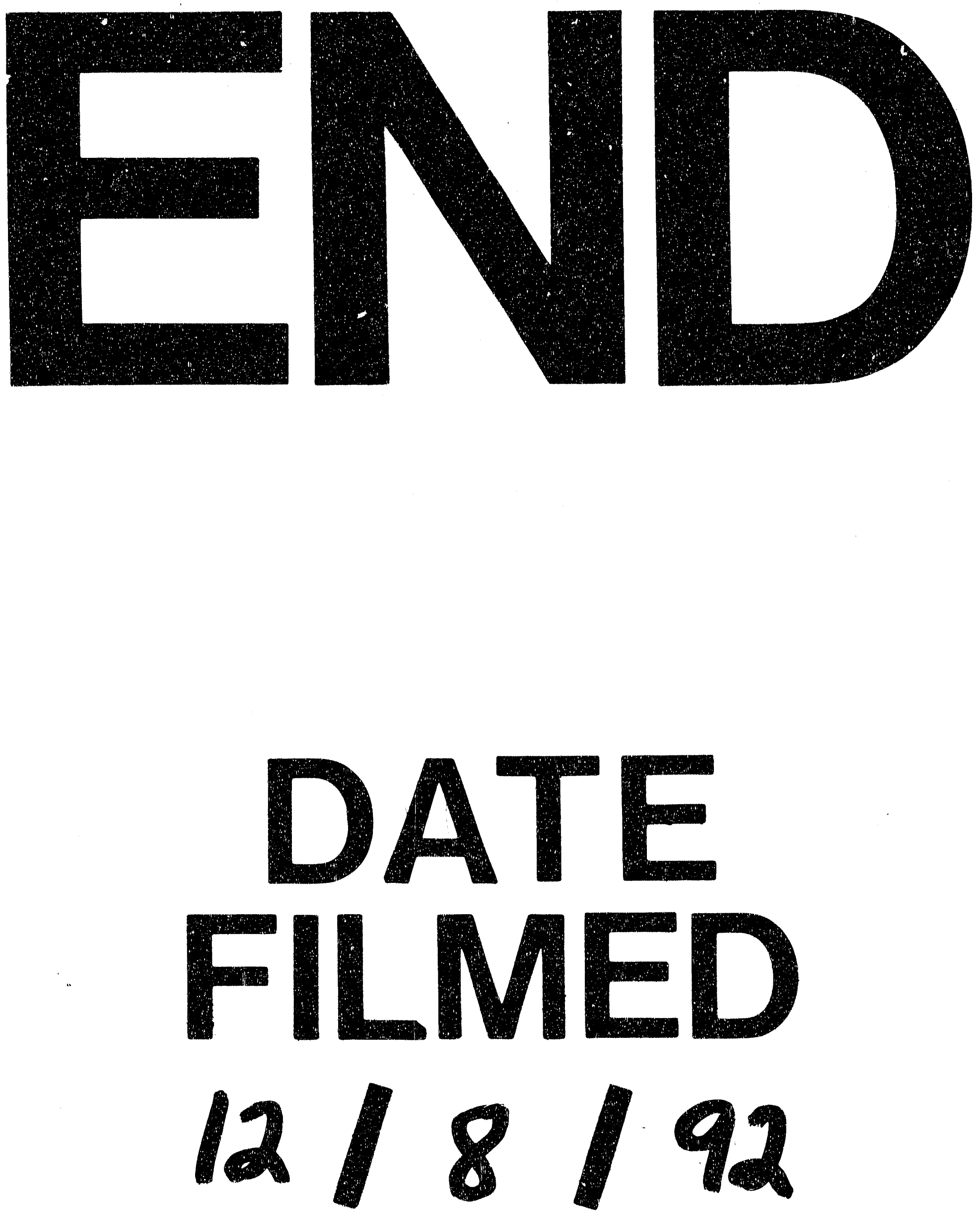
